\title{
Urothelial carcinoma of the renal pelvis with renal vein and inferior vena cava tumor thrombus: case series and literature review
}

\author{
Xiaojun Tian ${ }^{1 \#}$, Peng Hong ${ }^{1 \#}$, Shiying Tang ${ }^{1 \#}$, Zhuo Liu $^{1}$, Feilong Yang ${ }^{1,2}$, Shudong Zhang ${ }^{1}$, \\ Guoliang Wang ${ }^{1}$, Huiying $\mathrm{He}^{3}$, Lulin $\mathrm{Ma}^{1}$ \\ ${ }^{1}$ Department of Urology, Peking University Third Hospital, Beijing, China; ${ }^{2}$ Department of Urology, General Hospital of Ningxia Medical \\ University, Ningxia, China; ${ }^{3}$ Department of Pathology, Peking University Third Hospital, Beijing, China \\ Contributions: (I) Conception and design: X Tian, P Hong, S Tang, H He, L Ma; (II) Administrative support: S Tang, H He, L Ma; (III) Provision of \\ study materials or patients: F Yang, G Wang, S Zhang; (IV) Collection and assembly of data: Z Liu, F Yang, G Wang, S Zhang; (V) Data analysis and \\ interpretation: X Tian, P Hong, S Tang, Z Liu; (VI) Manuscript writing: All authors; (VII) Final approval of manuscript: All authors. \\ "These authors contributed equally to this work. \\ Correspondence to: Huiying He, MD. Department of Pathology, Peking University Third Hospital, 49 North Garden Road, Haidian District, Beijing \\ 100191, China. Email: huiyinghe@bjmu.edu.cn; Lulin Ma, MD. Department of Urology, Peking University Third Hospital, 49 North Garden Road, \\ Haidian District, Beijing 100191, China. Email: malulin@medmail.com.cn.
}

Background: Urothelial carcinoma (UC) of the renal pelvis with renal vein and inferior vena cava (IVC) tumor thrombus (TT) was extremely rare. We aimed to explore the clinical and pathological characteristics, diagnosis and treatment of renal pelvis UC with renal vein and IVC TT.

Methods: From March 2016 to January 2019, eight patients of renal pelvis UC with renal vein and IVC TT were diagnosed and underwent operation in our hospital. Clinical features, operative details, pathological outcomes, and prognosis data were reviewed and collected.

Results: There were five males and three females (52-84 years old). Their main symptoms were flank pain and hematuria. According to the Mayo classification, the TT was 4 level-0 (1 left and 3 right), 2 level-I (right), and 2 level-II (right). Half the patients underwent retroperitoneal laparoscopic radical nephroureterectomy with thrombectomy, and the other underwent open procedures. The mean operative time was 298.9 minutes. Pathological outcomes revealed high-grade UC, with positive lymph nodes in 6 cases. Four patients received adjuvant chemotherapy, one target therapy and one adjuvant chemotherapy combined with immunotherapy after surgery. The mean follow-up time was 11.1 months. Three patients are alive, and two of them developed recurrence and lung metastasis.

Conclusions: Preoperative differentiation between renal pelvis UC and renal cell carcinoma with venous TT was very important for the management. Radical nephroureterectomy with thrombectomy might be a reasonable method for renal pelvis UC with venous TT. The prognosis of such cases was poor even if adjuvant therapy was scheduled.

Keywords: Renal pelvis urothelial carcinoma; tumor thrombus (TT); treatment; prognosis; case series

Submitted Mar 23, 2021. Accepted for publication May 24, 2021.

doi: $10.21037 / \mathrm{tau}-21-253$

View this article at: https://dx.doi.org/10.21037/tau-21-253

\section{Introduction}

Urothelial carcinoma (UC) of the renal pelvis accounts for $5 \%$ of all UC (1). Renal vein and inferior vena cava (IVC) tumor thrombus (TT) usually develop in renal cell carcinoma (RCC), and the incidence of venous TT varies from $4 \%$ to $10 \%$ in RCC (2). However, the incidence of venous TT is extremely low in renal pelvic UC. It is reported that the incidence of IVC TT was 48 times higher in RCC than that in renal pelvis UC (3). Literatures 
reporting renal pelvis $\mathrm{UC}$ with venous TT were limited and there were only several case reports (4-24). There were eight patients with renal pelvis UC and venous TT undergoing surgery in our center. In this study, we reported our experience in the management of eight patients with renal pelvis $\mathrm{UC}$ and venous TT, and reviewed the pertinent literatures (25-29). We present the following article in accordance with the AME Case Series reporting checklist (available at https://dx.doi.org/10.21037/tau-21-253).

\section{Methods}

\section{Patients}

From March 2016 to January 2019, 247 patients were pathologically diagnosed with upper tract UC and underwent surgery at our institution. And there were only eight patients pathologically confirmed renal pelvis UC with venous TT during the study period at our institution. All the renal pelvis UC patients with venous TT underwent radical nephroureterectomy and thrombectomy. The study was conducted in accordance with the Declaration of Helsinki (as revised in 2013). The present study was approved by the Institutional Ethics Committee of our hospital (No. S2019229) and individual consent for this retrospective analysis was waived.

Clinical characteristics including age, gender, laterality, body mass index (BMI), symptoms, preoperative diagnosis, preoperative and postoperative serum creatinine ( $\mathrm{SCr}$ ), tumor node metastasis (TNM) stage, operative approach, pathological outcomes, adjuvant therapy, and prognosis data were collected and reviewed. Preoperative enhanced computed tomography (CT) (Figure 1) or magnetic resonance imaging (MRI) (Figure 2) were performed in all patients. The venous TT was classified according to Mayo Clinic classification (30). Perioperative complications were graded according to Clavien-Dindo system (31). All surgeries were performed for curative purpose. The surgical steps of radical nephrectomy and thrombectomy in our center were described in the previous publication (32), but we performed radical nephroureterectomy and thrombectomy when preoperative diagnosis was UC. For level-0 TT, renal vein was clamped before the entrance to IVC. For IVC TT, when TT did not invade the IVC wall, thrombectomy was performed and the incision of the IVC wall was sutured continuously (Figure 3). When TT invaded the IVC wall, the invaded IVC wall was resected. If the remaining IVC wall was more than half of the original diameter, the reconstruction was performed to prevent IVC stenosis. If it was less than half, there was no need for reconstruction. When TT circumferentially invaded the IVC wall, complete transection of the IVC was needed. There was no need of renal vein reconstruction for the left kidney because of abundant collateralization, but renal vein reconstruction is necessary for the right kidney in order to achieve sufficient blood reflux. Patients were advised to receive chemotherapy or immunotherapy after surgery according to their physical conditions and pathological outcomes. Patients were followed up every 3 months postoperatively. The median follow-up time of the patients was 11.5 months.

\section{Statistical analysis}

All analyses were performed with SPSS ${ }^{\circledR}$ Statistics, version 24.0 (IBM Corporation, Somers, NY, USA).

\section{Results}

The clinicopathological parameters, surgical variables and oncological outcomes of the eight patients were shown in Table 1. There were five males and three females. The mean age of the patients was 66.6 years (ranging from 52 to 84 years). Their main symptoms are flank pain $(n=4)$ and gross hematuria $(n=4)$. The preoperative diagnosis of 7 patients was renal pelvis UC and 1 patient was RCC. The mean tumor size was $6.7 \mathrm{~cm}$. Mayo Clinic classification demonstrated that there were 4 level-0 (1 left side and 3 right side), 2 level-I (right side), and 2 levelII (right side) venous TT. Half the patients underwent retroperitoneal laparoscopic radical nephroureterectomy with thrombectomy, and the other half underwent open procedures. Two of the patients underwent IVC transection, because of the circumferential invasion of the IVC wall. Besides, all the patients underwent lymph node dissection (LND). The perioperative mortality rate was $0 \%$. The mean operative time was 298.9 [197-494] minutes. The mean estimated blood loss was $493.8[100-1,700] \mathrm{mL}$, and three patients received blood transfusion. There was no significantly difference between the preoperative mean $\mathrm{SCr}$ $(98 \mu \mathrm{mol} / \mathrm{L})$ and the postoperative mean SCr $(99.5 \mu \mathrm{mol} / \mathrm{L})$ $(\mathrm{P}>0.05)$. One patient developed renal insufficiency and hyperkalemia, one cerebral infarction, and one chest distress after surgery. They gradually recovered after conservative therapy. The other patients had no procedure-related complications. The drainage tube was removed 3-13 days 


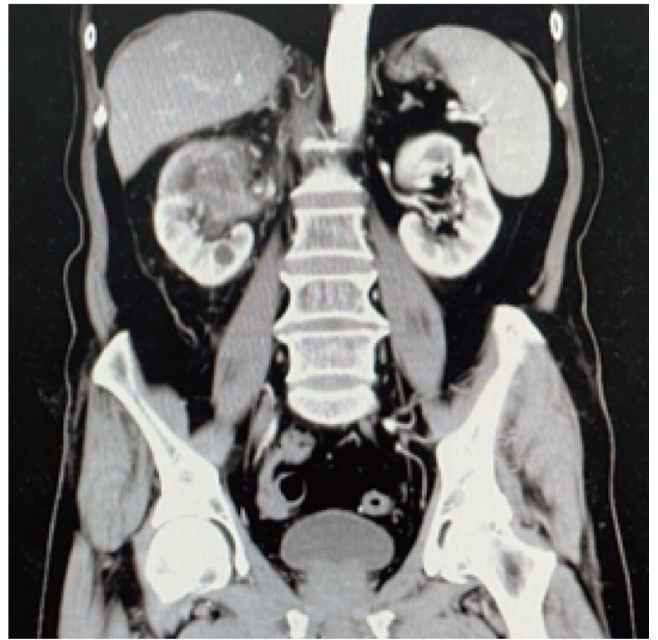

Figure $1 \mathrm{CT}$ image showing the right renal pelvis urothelial carcinoma and venous tumor thrombus.

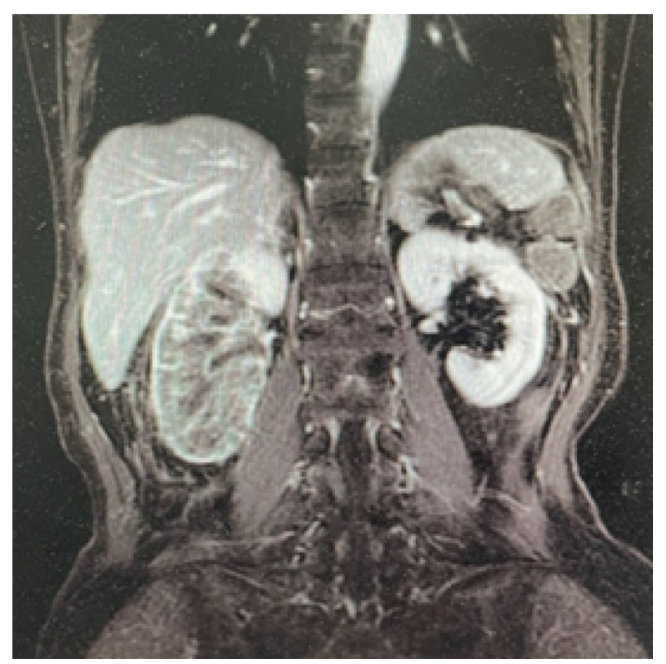

Figure 2 MRI image showing the right renal pelvis urothelial carcinoma and venous tumor thrombus.

after surgery, the mean time of removing drainage tube was 6.5 days. Postoperative pathology revealed renal pelvic high-grade UC (Figure 4). Six patients had lymph node metastasis.

Four patients underwent chemotherapy and one chemotherapy combined with immunotherapy after surgery. Two patients did not receive adjuvant therapy. Patient 2 received chemotherapy with gemcitabine and cis-platinum in another hospital. Patient 3 received chemotherapy with gemcitabine $(1.6 \mathrm{~g})$ and nedaplatin $(60 \mathrm{mg})$, and received radiotherapy for recurrence. Patient 4 had chemotherapy and immunotherapy in other hospital, but there was no detail recorded. Patient 5 had chemotherapy with gemcitabine and cis-platinum in another hospital. Patient 6 had chemotherapy with gemcitabine and cis-platinum in another hospital. Patient 7 was considered as RCC in another hospital and received targeted therapy before surgery. Then, she underwent surgery in our center, and pathological result showed UC. She did not receive adjuvant therapy after surgery.

All the patients were followed up. The mean follow-up time was 11.1 months, five patients died of UC after surgery. The survival time was 7, 9, 11, 11, 14 months, respectively. The disease-specific survival rate is $62.5 \%$. Three patients were alive, and two of them developed recurrence and lung metastasis. One patient had no metastasis or recurrence.

\section{Discussion}

Compared to RCC, renal pelvis UC with venous TT was extremely rare. We reviewed pertinent literatures, and found that there were only 49 patients reported and most literatures were case reports (Table 2). Our study reported 8 cases of renal pelvis UC with venous TT and it was the largest sample size report with detailed information at present.

In our study, the main symptoms of renal pelvic UC with venous TT were flank pain and gross hematuria, which were not specific. The diagnosis mainly relied on enhanced CT or MRI. CT, MRI, or angiography could effectively detect venous TT and evaluate the extent of venous TT. However, it is sometimes difficult to distinguish renal pelvis UC from RCC when the tumor is concomitant with TT. Because the imaging manifestations are not so specific. Thus, making correct preoperative diagnosis is not easy. In our study, Patient 1 was misdiagnosed as RCC before surgery. The CT and MRI of Patient 1 are Figure 5. It showed that an irregular low-density mass was in the right renal, and the reniform shape of the kidney was distorted. Given the rare incidence of renal pelvis UC with venous TT, the first patient in our center was considered as RCC.

A previous study demonstrated that CT was useful in distinguishing renal pelvis UC from RCC. The main identification points are as follows: (I) the tumor is in the center of the collecting system; (II) the pelvicalyceal system may present a focal filling defect; (III) no obvious changes appears in the reniform shape of the kidney; (IV) the tumor lacks necrotic or cystic change; (V) the tumor 

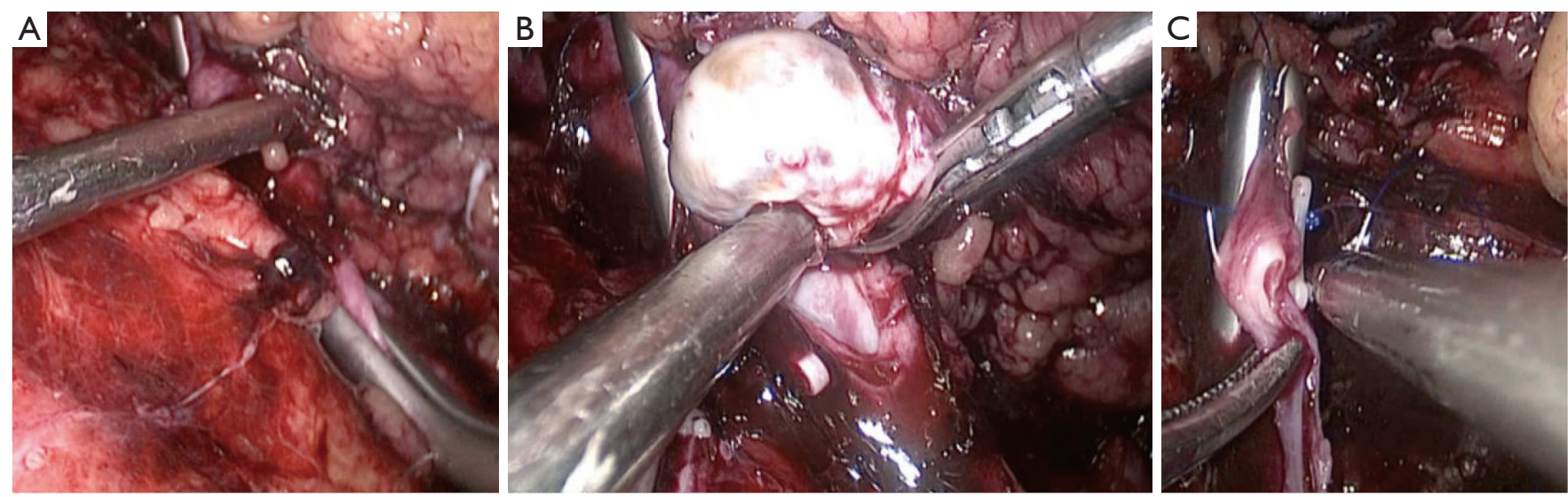

Figure 3 The intraoperative photographs of dealing with inferior vena cava tumor thrombus. (A) The inferior vena cava was clamped using a Satinsky clamp; (B) the inferior vena cava was incised, and the tumor thrombus was exposed; (C) the incision on the inferior vena cava then was sutured continuously.

exhibits homogeneous enhancement; and (VI) the tumor grows toward the ureteropelvic junction (33). Besides, Tseng et al. proposed that the infiltrating growth pattern and maintaining the reniform shape of kidney are more likely to indicate UC (23). Some researchers suggested that retrograde pyelography, urine cytology, and biopsy should be performed along with CT, and these tests were helpful for the differential diagnosis of renal pelvis tumor (34). It was crucial to make a proper preoperative diagnosis on the type of tumor, which determines the choice of the operative methods.

Open radical nephroureterectomy with thrombectomy was the safe and feasible treatment for renal pelvis UC with venous TT $(4,21)$. With the development of laparoscopic and robot-assisted laparoscopic technique, these minimally invasive methods were also applied to such cases (28). The exact role of surgery in the management of renal pelvis UC patients with venous TT is not defined, because of the limited available literature. In our opinion, for nonmetastatic renal pelvis UC patients with venous TT, surgery could reduce tumor loading, and might be helpful to improve the survival. We successfully performed retroperitoneal laparoscopic radical nephroureterectomy with thrombectomy in 4 patients and open procedures in the other four patients. Three patients developed complications after surgery. One patient developed renal insufficiency and hyperkalemia, one cerebral infarction, and one chest distress after surgery. In renal insufficiency case, the TT circumferentially invaded the IVC wall, and the complete transection of the involved IVC was performed. As the involved IVC was above renal vein level, the anastomosis of left renal vein and IVC was performed. We speculated that solitary kidney ischemia reperfusion injury and incomplete compensation of collateral circulation might cause the renal insufficiency. The renal function of the patient gradually recovered after conservative treatment. The complication rate was $37.5 \%$ in our study. Because the number of renal pelvis UC and venous TT reported is limited, the complications reported was also limited. Concepcion RS et al reported a UC patient with TT complicated by restrictive pulmonary insufficiency, resultant renal vein thrombosis and renal failure. And this patient died 31 days after surgery (13). Cerwinka et al. reported two patients complicated by pulmonary embolism (22). There was no complication rate of renal pelvis UC and venous TT reported. However, previous studies showed that radical nephrectomy with thrombectomy was related to major perioperative morbidity (range, 50-78\%) and mortality (range, 2.7-8.3\%) (35-37). Compared with this, we believe that our complication rate is acceptable.

Patients with renal pelvis UC and venous TT have a poor prognosis. Previous reports showed that 8 patients with renal pelvis UC and venous TT died within 6 months after surgery (20). In our study, five patients died of UC within 14 months after surgery, which is in agreement with the previous findings. Besides, the eight patients in our center had late stage (T3-4) and high-grade, which also might be related to the poor prognosis. As for TT, it has an influence on the prognosis of RCC. For renal pelvis UC, it is difficult to analysis the influence of TT on 
Table 1 Patients' clinicopathologic and operative characteristics

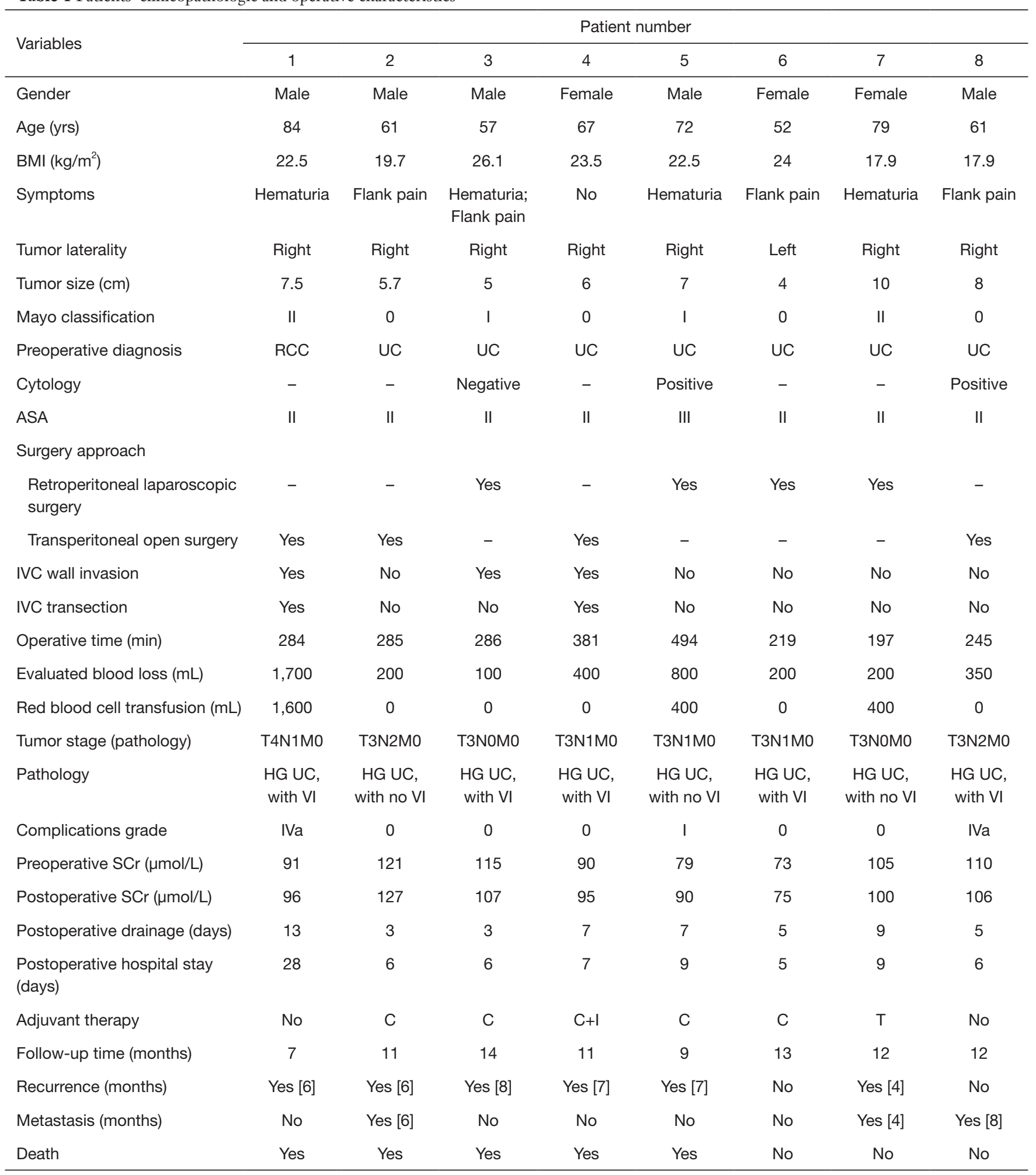

BMI, body mass index; RCC, renal cell carcinoma; UC, urothelial carcinoma; ASA, American Society of Anesthesiology; IVC, inferior vena cava; HG, high grade; VI, vascular invasion; SCr, serum creatinine; C, chemotherapy; I, immunotherapy; T, target therapy. 

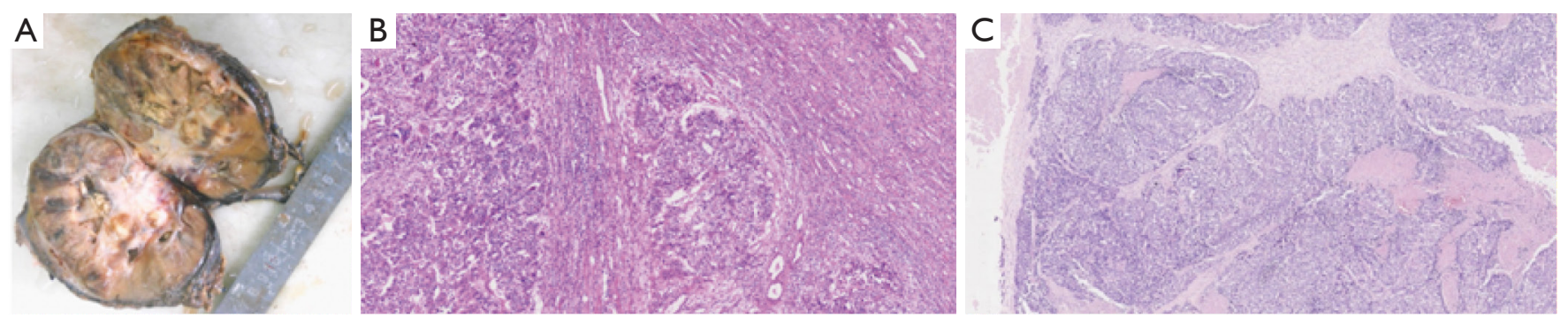

Figure 4 The macroscopic image and photomicrographs of the resected specimen. (A) The macroscopic image of specimen; (B) the pathological specimen shows urothelial carcinoma in the renal tumor (H\&E; original magnification, $\times 100)$; (C) the pathological specimen shows urothelial carcinoma in tumor thrombus (H\&E; original magnification, $\times 50$ ).

Table 2 Previous reported cases of renal pelvic UC with venous TT

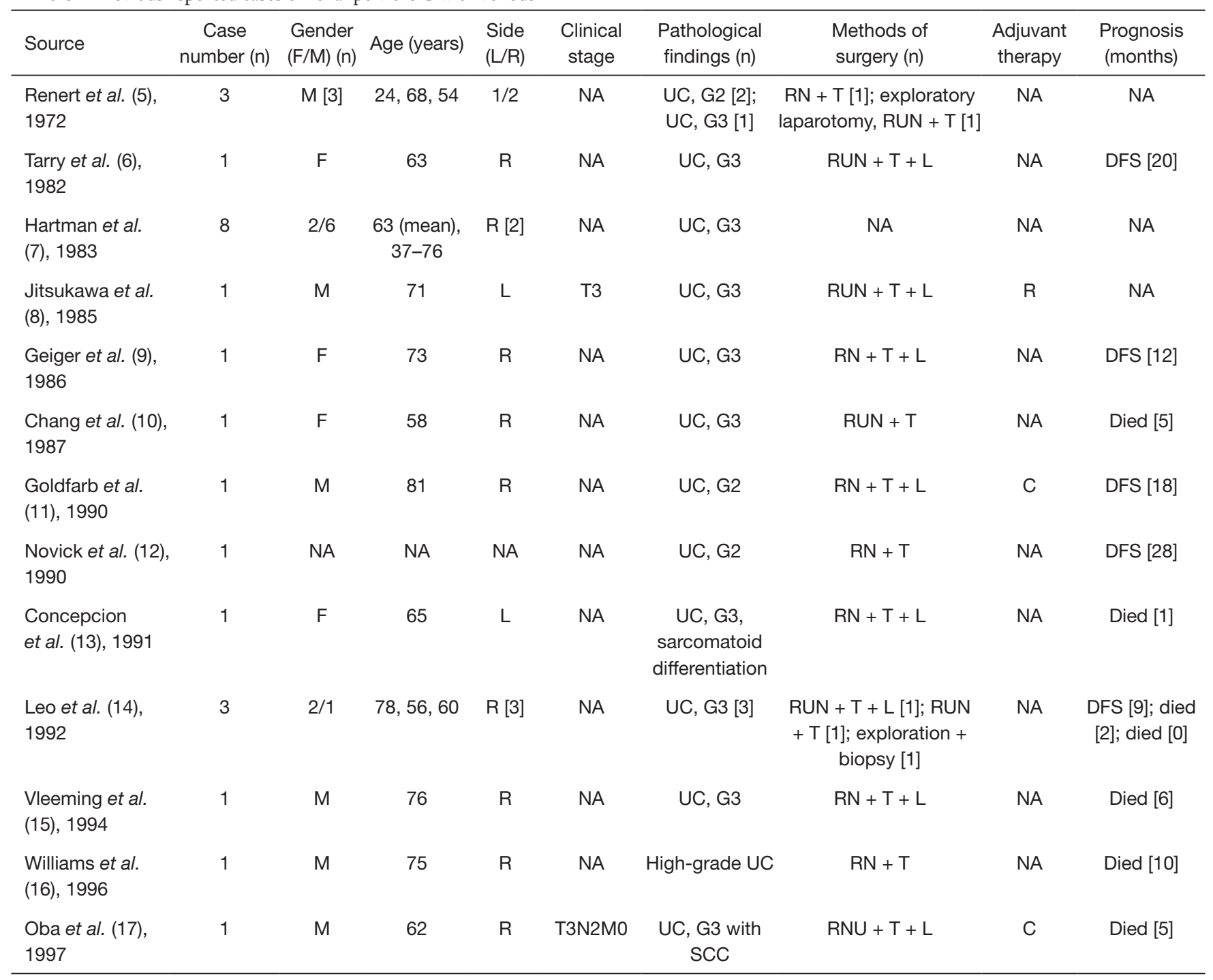

Table 2 (continued) 
Table 2 (continued)

\begin{tabular}{|c|c|c|c|c|c|c|c|c|c|}
\hline Source & $\begin{array}{c}\text { Case } \\
\text { number (n) }\end{array}$ & $\begin{array}{l}\text { Gender } \\
(\mathrm{F} / \mathrm{M})(\mathrm{n})\end{array}$ & Age (years) & $\begin{array}{l}\text { Side } \\
(\mathrm{L} / \mathrm{R})\end{array}$ & $\begin{array}{l}\text { Clinical } \\
\text { stage }\end{array}$ & $\begin{array}{l}\text { Pathological } \\
\text { findings }(n)\end{array}$ & $\begin{array}{l}\text { Methods of } \\
\text { surgery (n) }\end{array}$ & $\begin{array}{l}\text { Adjuvant } \\
\text { therapy }\end{array}$ & $\begin{array}{l}\text { Prognosis } \\
\text { (months) }\end{array}$ \\
\hline $\begin{array}{l}\text { Tajima et al. (18), } \\
1997\end{array}$ & 1 & M & 72 & $\mathrm{R}$ & T3 & UC, G2-3 & $\begin{array}{l}\text { Percutaneous needle } \\
\text { biopsy }\end{array}$ & C & DFS [12] \\
\hline $\begin{array}{l}\text { Fujimoto et al. } \\
(19), 1997\end{array}$ & 1 & $\mathrm{~F}$ & 64 & $\mathrm{R}$ & $\mathrm{T} 4$ & High-grade UC & $\mathrm{RUN}+\mathrm{T}$ & C & DFS [20] \\
\hline $\begin{array}{l}\text { Juan et al. (21), } \\
2003\end{array}$ & 2 & F [2] & 50,72 & $\mathrm{R}$ [2] & T3 [2] & $\begin{array}{l}\text { High-grade UC, } \\
\text { necrotic cancer } \\
\text { cells [1]; UC [1] }\end{array}$ & $\begin{array}{c}\mathrm{RN}+\text { incompletely } \\
\mathrm{T}[1] ; \\
\text { no therapy [1] }\end{array}$ & NA & Died $[0.75,5]$ \\
\hline $\begin{array}{l}\text { Cerwinka et al. } \\
\text { (22), } 2009\end{array}$ & 2 & NA & NA & $\mathrm{R}$ [2] & $\begin{array}{l}\text { T3NOMx; } \\
\text { T4N2Mx }\end{array}$ & High-grade UC & Surgery (no detail) & C [1] & $\begin{array}{l}\text { Local } \\
\text { recurrence } \\
{[2,8]}\end{array}$ \\
\hline $\begin{array}{l}\text { Young et al. (24), } \\
2012\end{array}$ & 1 & M & 34 & $\mathrm{R}$ & $\mathrm{T} 4$ & High-grade UC & $\mathrm{RN}$ & NA & NA \\
\hline $\begin{array}{l}\text { Nam et al. (25), } \\
2012\end{array}$ & 1 & M & 67 & $\mathrm{R}$ & T4N1M0 & UC, G3 & $\begin{array}{l}\text { RUN with IVC } \\
\text { replacement }\end{array}$ & NA & DFS [9] \\
\hline $\begin{array}{l}\text { Pirola et al. (26), } \\
2013\end{array}$ & 4 & NA & NA & NA & T3-4 N+M+ & UC, G3 & $R U N+T$ & C & $\begin{array}{c}\text { OS }(14.25, \\
\text { mean) }[11-18]\end{array}$ \\
\hline $\begin{array}{l}\text { Diaz et al. (27), } \\
2014\end{array}$ & 1 & M & 61 & $\mathrm{R}$ & T4NOMO & $\begin{array}{l}\text { High-grade UC, } \\
\text { sarcomatoid } \\
\text { differentiation }\end{array}$ & $R N+T+L$ & C & NA \\
\hline Li et al. (4), 2016 & 3 & $1 / 2$ & $73,58,68$ & $\begin{array}{l}\mathrm{L}[2] \\
\mathrm{R}[1]\end{array}$ & $\begin{array}{l}\text { T4TN3M0; } \\
\text { T3NOM0; } \\
\text { T3N1M0 }\end{array}$ & $\begin{array}{l}\text { High-grade } \\
\text { UC [3] }\end{array}$ & $\begin{array}{c}\text { RUN + T + L [1]; } \\
\text { RN + T [1]; } \\
\text { RUN + T + L [1] }\end{array}$ & $\begin{array}{c}C[1] \\
C+R[1]\end{array}$ & Died $[2,3,19]$ \\
\hline $\begin{array}{l}\text { Singh et al. (29), } \\
2017\end{array}$ & 1 & $\mathrm{~F}$ & 55 & $\mathrm{R}$ & NA & High-grade UC & $\mathrm{RN}+\mathrm{T}+\mathrm{L}$ & $\mathrm{C}$ & NA \\
\hline
\end{tabular}

UC, urothelial carcinoma; TT, tumor thrombus; F, female; M, male; L, left; R, right; NA, not available; G, grade; RN, radical nephrectomy; RNU, radical nephroureterectomy; T, thrombectomy; L, lymphadenectomy; C, chemotherapy; R, radiation; SCC, squamous cell carcinoma; DFS, disease free survival; OS, overall survival.

patient, because of the limited number of patients. On the whole, we believe that both TT and unfavorable pathology had a bad influence on prognosis. For the eight patients, chemotherapy was the primary adjuvant therapy (5/8). At that time, no clear evidence exists either to support or oppose the use of neoadjuvant chemotherapy. And some patients' performance status was poor and some patients in our study refused to receive neoadjuvant chemotherapy. Thus, these patients were not offered neoadjuvant cisplatinbased chemotherapy in our study. Compared with adjuvant 

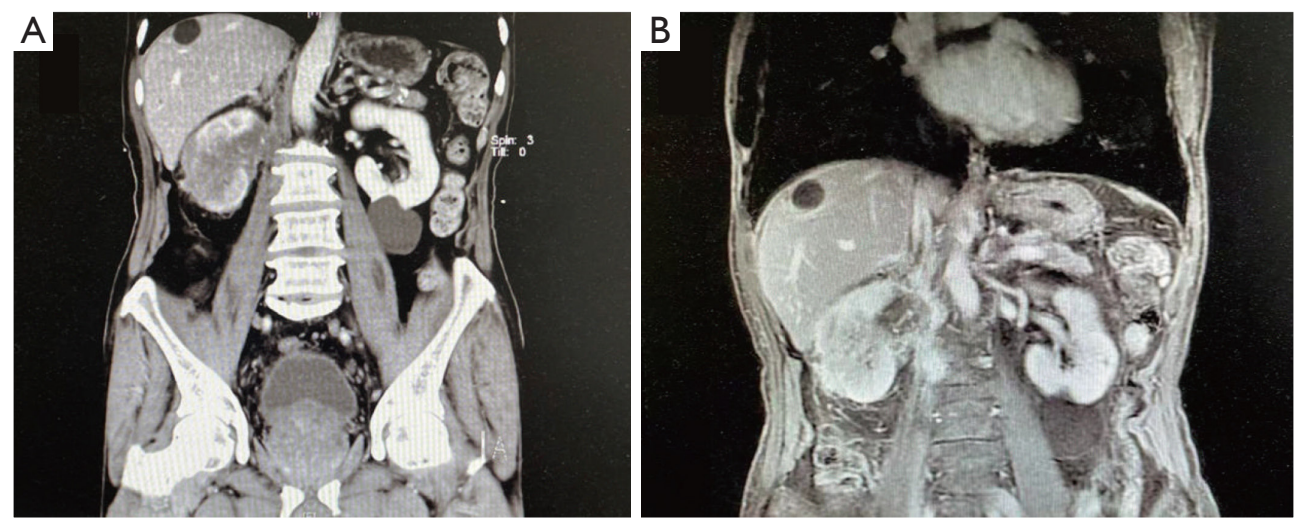

Figure 5 The imaging pictures of Patient 1. (A) The CT image of Patient 1; (B) the MRI image of Patient 1.

chemotherapy, the neoadjuvant therapy may reach a better outcome, because some patients might not be tolerance to chemotherapy after nephrectomy. However, if neoadjuvant chemotherapy is considered, the diagnosis should be assured by pathological examination. Besides, the patient's preference and performance status should be taken into consideration when choosing neoadjuvant therapy.

We admit that the current study has some limitations. First, its retrospective nature is a shortcoming, and may cause some bias. Second, the sample size of this study is small, due to the low incidence of renal pelvis UC with venous TT. Thus, a multi-center study with large sample size is needed. Third, the follow-up time was short. Fourth, all the patients in this study did not have neoadjuvant cisplatin-bases chemotherapy. Thus, we cannot evaluate the therapeutic effect of neoadjuvant chemotherapy.

\section{Conclusions}

Renal pelvis UC with renal vein and IVC TT is rare. A correct preoperative diagnosis is greatly important to determine surgical strategy. Radical nephroureterectomy with thrombectomy was a safe and feasible operative method in such cases. Chemotherapy was the main adjuvant therapy option. However, the prognosis of renal pelvis UC and venous TT is very poor. More cases are needed for further research.

\section{Acknowledgments}

We are grateful to the entire staff in Department of Urology, Peking University Third Hospital.

Funding: This work was supported by Key Clinical Projects of Peking University Third Hospital (BYSYZD2019032) and the Fundamental Research Funds for the Central Universities: Special Projects for Strengthening Basic Research of Peking University (BMU2019JC001).

\section{Footnote}

Reporting Checklist: The authors have completed the AME Case Series reporting checklist. Available at https://dx.doi. org/10.21037/tau-21-253

Data Sharing Statement: Available at https://dx.doi. org/10.21037/tau-21-253

Peer Review File: Available at https://dx.doi.org/10.21037/ tau-21-253

Conflicts of Interest: All authors have completed the ICMJE uniform disclosure form (available at https://dx.doi. org/10.21037/tau-21-253). The authors have no conflicts of interest to declare.

Ethical Statement: The authors are accountable for all aspects of the work in ensuring that questions related to the accuracy or integrity of any part of the work are appropriately investigated and resolved. The study was conducted in accordance with the Declaration of Helsinki (as revised in 2013). The present study was approved by the Institutional Ethics Committee of our hospital (No. S2019229) and individual consent for this retrospective analysis was waived.

Open Access Statement: This is an Open Access article 
distributed in accordance with the Creative Commons Attribution-NonCommercial-NoDerivs 4.0 International License (CC BY-NC-ND 4.0), which permits the noncommercial replication and distribution of the article with the strict proviso that no changes or edits are made and the original work is properly cited (including links to both the formal publication through the relevant DOI and the license). See: https://creativecommons.org/licenses/by-nc-nd/4.0/.

\section{References}

1. Hall MC, Womack S, Sagalowsky AI, et al. Prognostic factors, recurrence and survival in transitional cell carcinoma of the upper urinary tract: a 30-year experience in 252 patients. Urology 1998;52:594-601.

2. Benkirane A, Khodari M, Yakoubi R, et al. Polytetrafluoroethylene expanded prosthesis as replacement of the inferior vena cava in renal cell carcinoma with caval thrombus. Int J Urol 2014;21:448-52.

3. Huber J, Teber D, Hatiboglu G, et al. Does a venous tumor thrombus exclude renal transitional cell carcinoma? Implications for neo-adjuvant treatment strategies. Anticancer Res 2014;34:1031-5.

4. Li M, Shi A, Kong W, et al. Transitional cell carcinoma with extension of the renal vein and IVC tumor thrombus: report of three cases and literature review. World J Surg Oncol 2016;14:309.

5. Renert WA, Rudin LJ, Casarella WJ. Renal vein thrombosis in carcinoma of the renal pelvis. Am J Roentgenol Radium Ther Nucl Med 1972;114:735-40.

6. Tarry WF, Morabito RA, Belis JA. Carcinosarcoma of the renal pelvis with extension into the renal vein and inferior vena cava. J Urol 1982;128:582-5.

7. Hartman DS, Pyatt RS, Dailey E. Transitional cell carcinoma of the kidney with invasion into the renal vein. Urol Radiol 1983;5:83-7.

8. Jitsukawa S, Nakamura K, Nakayama M, et al. Transitional cell carcinoma of kidney extending into renal vein and inferior vena cava. Urology 1985;25:310-2.

9. Geiger J, Fong Q, Fay R. Transitional cell carcinoma of renal pelvis with invasion of renal vein and thrombosis of subhepatic inferior vena cava. Urology 1986;28:52-4.

10. Chang SY, Ma CP. Transitional cell carcinoma of the kidney with extension into the inferior vena cava. Eur Urol 1987;13:287-8.

11. Goldfarb DA, Lorig R, Zelch $M$, et al. Right renal mass with vena caval thrombus. J Urol 1990;143:574-7.
12. Novick AC, Kaye MC, Cosgrove DM, et al. Experience with cardiopulmonary bypass and deep hypothermic circulatory arrest in the management of retroperitoneal tumors with large vena caval thrombi. Ann Surg 1990;212:472-6.

13. Concepcion RS, Koch MO, McDougal WS, et al. Management of primary nonrenal parenchymal malignancies with vena caval thrombus. J Urol 1991;145:243-7.

14. Leo ME, Petrou SP, Barrett DM. Transitional cell carcinoma of the kidney with vena caval involvement: report of 3 cases and a review of the literature. J Urol 1992;148:398-400.

15. Vleeming R, Blaauwgeers HL, Karthaus PP, et al. Pulmonary tumour and inferior vena cava tumour thrombus: rare presentation of renal transitional cell carcinoma. Case report. Scand J Urol Nephrol 1994;28:419-23.

16. Williams JH, Frazier HA 2nd, Gawith KE, et al. Transitional cell carcinoma of the kidney with tumor thrombus into the vena cava. Urology 1996;48:932-5.

17. Oba K, Suga A, Shimizu Y, et al. Transitional cell carcinoma of the renal pelvis with vena caval tumor thrombus. Int J Urol 1997;4:307-10.

18. Tajima T, Yoshimitsu K, Honda H, et al. Hypervascular renal transitional cell carcinoma with extension into the renal vein and inferior vena cava. Comput Med Imaging Graph 1997;21:365-8.

19. Fujimoto $M$, Tsujimoto $Y$, Nonomura N, et al. Renal pelvic cancer with tumor thrombus in the vena cava inferior. A case report and review of the literature. Urol Int 1997;59:263-5.

20. Miyazato M, Yonou H, Sugaya K, et al. Transitional cell carcinoma of the renal pelvis forming tumor thrombus in the vena cava. Int J Urol 2001;8:575-7.

21. Juan YS, Jang MY, Shen JT, et al. Transitional cell carcinoma of the renal pelvis with extension into the inferior vena cava: a report of two cases. Kaohsiung J Med Sci 2003;19:362-7.

22. Cerwinka WH, Manoharan M, Soloway MS, et al. The role of liver transplantation techniques in the surgical management of advanced renal urothelial carcinoma with or without inferior vena cava thrombus. Int Braz J Urol 2009;35:19-23.

23. Tseng YS, Chen KH, Chiu B, et al. Renal urothelial carcinoma with extended venous thrombus. South Med J 2010;103:813-4.

24. Young A, Kunju LP. High-grade carcinomas involving the renal sinus: report of a case and review of the differential 
diagnosis and immunohistochemical expression. Arch Pathol Lab Med 2012;136:907-10.

25. Nam JK, Moon KM, Park SW, et al. Surgical treatment of inferior vena cava invasion in patients with renal pelvis transitional cell carcinoma by use of human cadaveric aorta. Korean J Urol 2012;53:285-7.

26. Pirola GM, Saredi G, Damiano G, et al. Renal cell carcinoma with venous neoplastic thrombosis: a ten years review. Arch Ital Urol Androl 2013;85:175-9.

27. Diaz RR, Kwon JK, Lee JY, et al. Renal pelvic urothelial carcinoma with vena caval thrombus mimicking renal cell carcinoma. Korean J Urol 2014;55:624-7.

28. Wang W, Wang L, Xu J, et al. Pure retroperitoneal laparoscopic radical nephrectomy for right renal masses with renal vein and inferior vena cava thrombus. J Endourol 2014;28:819-24.

29. Singh O, George AJP, Singh JC, et al. Transitional cell carcinoma of the renal pelvis with venous tumor thrombus. Rev Urol 2017;19:145-8.

30. Blute ML, Leibovich BC, Lohse CM, et al. The Mayo Clinic experience with surgical management, complications and outcome for patients with renal cell carcinoma and venous tumor thrombus. BJU Int 2004;94:33-41.

31. Dindo D, Demartines N, Clavien PA. Classification of surgical complications: a new proposal with evaluation in a cohort of 6336patients and results of a survey. Ann Surg 2004;240:205-13.

Cite this article as: Tian $\mathrm{X}$, Hong $\mathrm{P}$, Tang S, Liu Z, Yang F, Zhang S, Wang G, He H, Ma L. Urothelial carcinoma of the renal pelvis with renal vein and inferior vena cava tumor thrombus: case series and literature review. Transl Androl Urol 2021;10(7):2879-2888. doi: 10.21037/tau-21-253
32. Tian X, Hong P, Liu Z, et al. En bloc retroperitoneal laparoscopic radical nephrectomy with inferior vena cava thrombectomy for renal cell carcinoma with level 0 to II venous tumor thrombus: A single-center experience. Cancer 2020;126 Suppl 9:2073-8.

33. Raza SA, Sohaib SA, Sahdev A, et al. Centrally infiltrating renal masses on CT: differentiating intrarenal transitional cell carcinoma from centrally located renal cell carcinoma. AJR Am J Roentgenol 2012;198:846-53.

34. Taneja SS. Re: centrally infiltrating renal masses on CT: differentiating intrarenal transitional cell carcinoma from centrally located renal cell carcinoma. J Urol 2012;188:1719-20.

35. Haddad AQ, Leibovich BC, Abel EJ, et al. Preoperative multivariable prognostic models for prediction of survival and major complications following surgical resection of renal cell carcinoma with suprahepatic caval tumor thrombus. Urol Oncol 2015;33:388.e1-9.

36. Ebbing J, Wiebach T, Kempkensteffen C, et al. Evaluation of perioperative complications in open and laparoscopic surgery for renal cell cancer with tumor thrombus involvement using the Clavien-Dindo classification. Eur J Surg Oncol 2015;41:941-52.

37. Toren P, Abouassaly R, Timilshina N, et al. Results of a national population-based study of outcomes of surgery for renal tumors associated with inferior vena cava thrombus. Urology 2013;82:572-7. 